\title{
Cystic angiomatosis of the bone appearing as intrathoracic lung masses
}

\author{
Tomas Pulido-Zamudio MD, William Orr MD, Morley Lertzman MD FRCPC \\ Departments of Medicine and Pathology, University of Manitoba, \\ St Boniface General Hospital, Winnipeg, Manitoba
}

\section{T Pulido-Zamudio, W Orr, M Lertzman. Cystic angio- matosis of the bone appearing as intrathoracic lung masses. Can Respir J 2001;8(3):187-190.}

A rare case of cystic angiomatosis of the bone $(\mathrm{CAB})$ manifesting as bilateral intrathoracic masses is described. In 1996, a 47-year-old woman was referred to the chest clinic at St Boniface Hospital for evaluation of chronic cough, and her chest radiograph showed large, bilateral pleural-based intrathoracic masses. Ten years before, she had been diagnosed with $\mathrm{CAB}$ following bone biopsies of her hip and knee. Computed tomography revealed two chest wall masses with internal septations of bone. $\mathrm{CAB}$ is a rare, multicentric disease characterized by involvement of the vascular and lymphatic systems, producing diffuse cystic lesions in the skeleton. Although the ribs are frequently involved, the presentation with intrathoracic masses is uncommon.

Key Words: Cystic angiomatosis; Intrathoracic mass; Lytic bone lesions

\section{Angiomatose kystique de l'os prenant l'appa- rence de masses pulmonaires intrathoraciques}

RÉSUMÉ : On décrit ici un cas rare d'angiomatose kystique de l'os (AKO) prenant l'apparence de masses intrathoraciques bilatérales. En 1996, une femme de 47 ans a été envoyée en consultation en raison d'une toux chronique et de masses intrathoraciques bilatérales au niveau des plèvres à la radiographie pulmonaire. Dix ans auparavant, elle avait reçu un diagnostic d'AKO après biopsie osseuse de la hanche et du genou. La tomographie a révélé deux masses à la paroi pulmonaire avec apparition de cloisonnements osseux internes. L'AKO est une maladie diffuse rare caractérisée par une atteinte des systèmes vasculaires et lymphatiques qui produit des lésions squelettiques kystiques éparses. Les côtes sont souvent affectées, les masses intrathoraciques sont plus rares.
$\mathrm{C}$ ystic angiomatosis of the bone $(\mathrm{CAB})$ is a rare, multicentric disease that involves both the vascular and lymphatic systems, producing diffuse cystic lesions in the skeleton that are often accompanied by visceral involvement, especially the spleen. As of 1999, 56 cases have been reported in the medical literature. There is a wide range of clinical manifestations, from a mild, asymptomatic form to a very severe form that can lead to early death (1). Both the appendicular and the axial skeleton can be affected, and the ribs are frequently involved. The typical appearance is one of multiple, small round or oval intraosseous cysts. We present the case of a 47-year-old woman with rib lesions appearing as intrathoracic masses; to our knowledge, this is the first such case in the literature. 

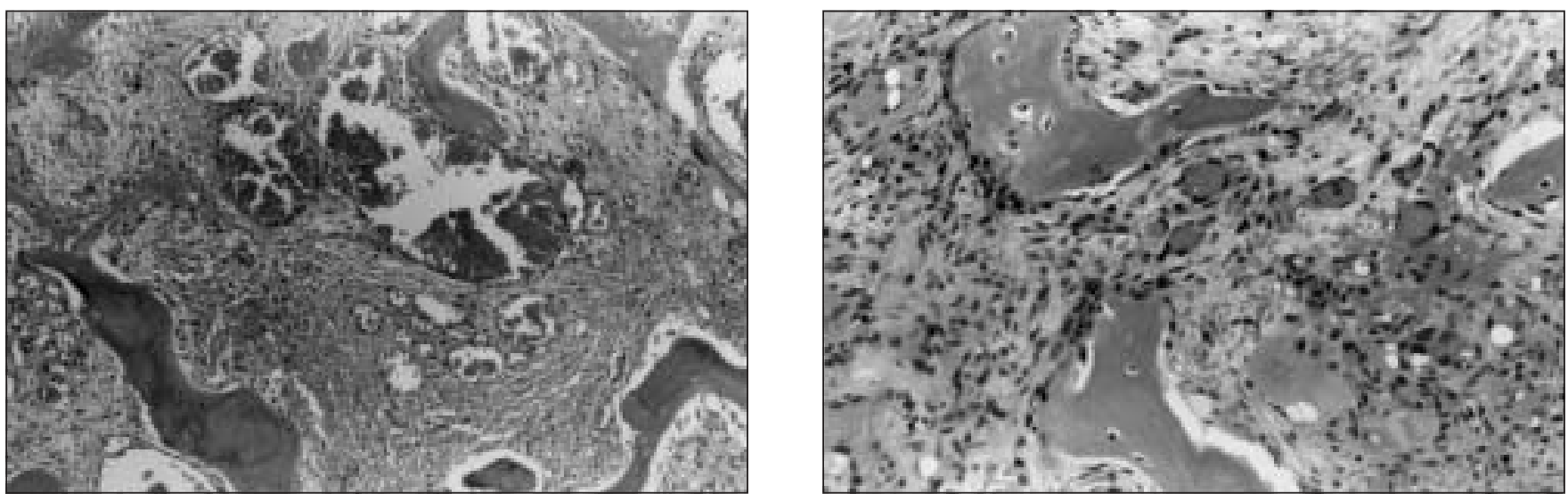

Figure 1) Left Bone biopsy showing replacement of the intramedullary marrow space by a population of blood-filled vessels of variable size, lined by a single layer of well differentiated endothelium. The vessels are supported by a fibrous stroma. Right There is prominent osteoclastic resorption of trabecular bone adjacent to the vasoformative lesions. In places, collections of osteoclasts and stroma resemble the lesions seen in osteitis fibrosa cystica. (Hematoxylin and eosin stain, original magnification $\times 400$ )

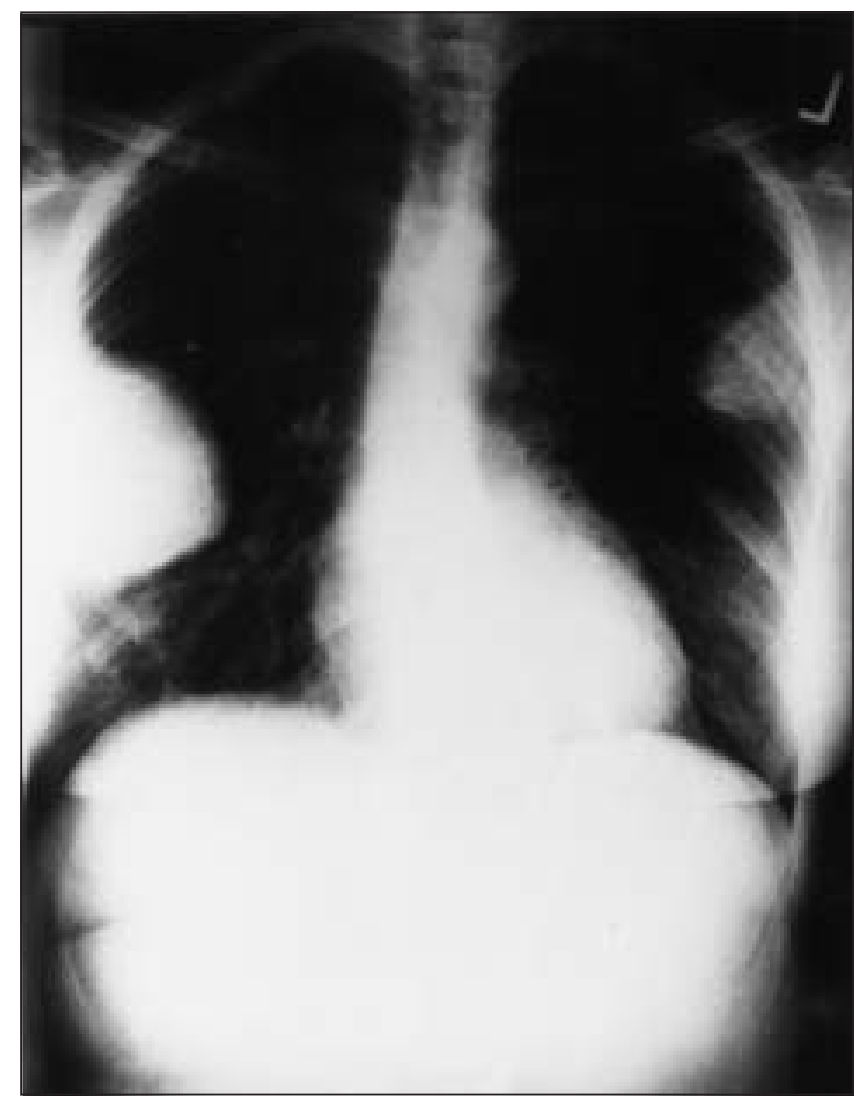

Figure 2) Chest radiograph showing bilateral rib masses arising from the right fifth and left third ribs

\section{CASE PRESENTATION}

A 47-year-old woman was referred to the chest clinic at St Boniface General Hospital, Winnipeg, Manitoba, for evaluation of chronic cough of three to four years' duration. She had been a minimal smoker - up to a package a day between the ages of 16 and 23 years. Ten years before, she was diagnosed with $\mathrm{CAB}$ following bone biopsies of her right knee and hip (Figure 1). She was told at that time that her chest radiograph was normal.

Her cough was usually dry with occasional white sputum, and was triggered by cold air and strong odors. She was aware of mild postnasal drip and had no symptoms of gastroesophageal reflux. Her exercise tolerance was normal. On physical examination, her chest had hard palpable masses over the right fifth and left third ribs. The remainder of the examination was normal. Routine complete blood count (CBC), liver function tests and chemistry, including calcium, were all normal. Office spirometry showed a forced expiratory volume in $1 \mathrm{~s}\left(\mathrm{FEV}_{1}\right)$ of $2.6 \mathrm{~L} / \mathrm{s}$ and a forced vital capacity (FVC) of $3.2 \mathrm{~L} / \mathrm{s}$. A methacholine challenge was positive at $4 \mathrm{mg}$ and showed mild to moderate airway hyperreactivity.

A chest radiograph showed two well-marginated masses within the thorax $-68 \mathrm{~cm}$ on the right side and $4.55 \mathrm{~cm}$ on the left side (Figure 2). The angle of junctions with the pleura was obtuse superiorly and acute inferiorly. A computed tomography (CT) scan confirmed the presence of the two masses, arising from the fifth right rib with displacement of the serratus anterior muscle and from the third left rib anterolaterally. Both masses contained internal septations of bone (Figure 3). Similar lesions were found in the lower thoracic vertebrae without expansion.

A diagnosis of asthma was made, and the patient was treated with inhaled fluticasone $250 \mathrm{~g}$ bid and salbutamol as required, with improvement in her symptoms. A two-year follow-up chest radiograph showed no changes in the size of the lesions, and the patient remains asymptomatic.

\section{DISCUSSION}

Cystic angiomatosis of the bone is a rare but pathologically distinct entity characterized by multiple cysts scattered diffusely throughout the skeleton, which are often associated with similar changes in other tissues, notably the spleen (1-3). A wide variety of diagnostic terms such as 'lymphangiomatosis', 'hemangiomatosis' and 'hamartous lymphangiomatosis' of the bone have been used; however, 

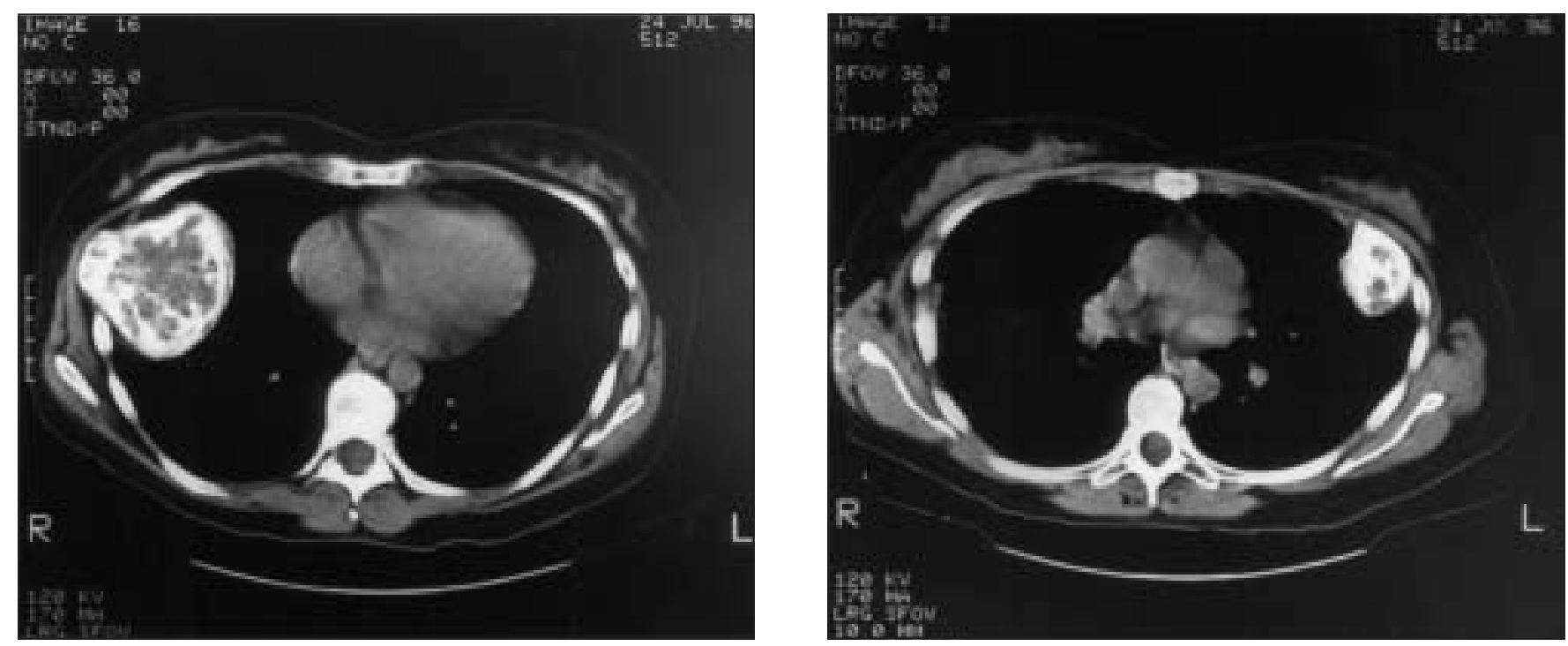

Figure 3) Computed tomography $(C T)$ chest scan showing masses arising from the right fifth and left third ribs, with internal septations of bone. The CT slice thickness was $10 \mathrm{~mm}$. No contrast was used

the term ' $\mathrm{CAB}$ ' is preferred because some cases have been described that contained either isolated hemangiomas or lymphangiomas, or a mixture of both vascular components (2-5). In addition, it is often impossible to differentiate hemangioma from lymphangioma, not only histopathologically but also clinically and radiologically (4).

$\mathrm{CAB}$ usually presents during the first three decades of life, although this disorder has also been diagnosed in elderly patients (the oldest patient was 69 years of age) (3). It had been reported to have a greater incidence in men (6); however, a recent review showed no significant sex predominance (3). The clinical manifestations and course of the disease depend largely on the presence or absence of visceral involvement. When soft tissue is involved, the spleen is almost always affected. Other organs that may be involved include the liver, kidney, pleural and peritoneal membranes, mesentery, retroperitoneum and lymph nodes $(1,3)$. There is a wide range of clinical manifestations; the most common are soft tissue swelling, incidental findings on plain radiograph or pathological fracture (3). Other uncommon forms of presentation are dyspnea, hemoptysis, lymphedema, pleural effusion, splenomegaly, hepatomegaly, soft tissue masses and pneumocephalus $(1,6,7)$.

The typical course of $\mathrm{CAB}$ in patients without visceral involvement is relatively benign and compatible with a long life span. When there is both visceral and skeletal involvement, there may be a progressive course that can lead to an early death $(1,3,6)$. Although there have been reports of cases of spontaneous regression, the majority of these patients had skeletal involvement only (1).

In the present patient, the clinical manifestations were minimal. The chronic cough that the patient complained of during her visit was thought to be due to cough-variant asthma.

The radiographic abnormalities found in $\mathrm{CAB}$ are lytic, well-defined round or oval lesions of the medullary cavity with preserved cortex and sclerotic borders, little residual central trabeculation and no periosteal reaction $(3,8)$. Sclerotic lesions, and mixed lytic and sclerotic lesions, have also been described, especially in older patients $(4,9)$. CT and magnetic resonance imaging can be used to confirm the character of the lesions $(8,10)$. The magnetic resonance imaging can characterize the lesions as endothelium-lined cysts, a characteristic that sometimes cannot be noted with CT (10).

The pathological diagnosis of $\mathrm{CAB}$ should be made in association with typical radiographic findings and clinical features; it has been found that of all the bones that appear to be involved, the rib provides the highest diagnostic yield (3). Macroscopically, the lesion may resemble a typical bone cyst. The microscopic appearance is of dilated, cavernous vascular channels surrounded by a single layer of flattened endothelial cells, which may be of blood vessel or lymphatic origin, as indicated by their contents $(1,6)$. This distinction can sometimes be difficult to make, especially if the cystic spaces are filled with fluid. Patients with $C A B$ have been described who have lymphangiomas at one site and typical hemangiomas at others (6).

In addition to showing the replacement of the marrow space by vascular channels, bone biopsies in the present patient showed large focal areas with active osteoclastic bone resorption. These areas were located directly adjacent to the vascular intramedullary stroma, in places resembling the features of osteitis fibrosa cystica.

The pathogenesis is not well understood but seems to favour the theory that these cystic lesions are the result of vascular malformations of congenital origin rather than representing true neoplasms $(1,9)$, and that the osteolytic lesions are the result of pressure atrophy, hyperemia or progressive dilation of lymphatics with secondary bone resorption. The features in the present patient suggest that osteoclastic bone resorption may contribute to the osteolytic properties of these lesions - a dominant radiological manifestation of $\mathrm{CAB}$. While an osteoblastic reaction has been documented in 
some patients (4), active osteoclastic bone resorption does not appear to have been emphasized in previous descriptions of the histology. More difficult to explain is the lack of biological control of this vascular network that allows cystic dilation and proliferation to occur. One possibility is that recanalization and subsequent distention of a pre-existing malformation occur, and only when symptoms result does this come to the attention of the patient (3).

There is no specific treatment for the bony lesions. Local radiation and chemotherapy have been used in progressive cases without any change in the clinical course of the disease. Corrective orthopedic procedures and treatment of pathological fractures are indicated $(2,3)$.

The differential diagnosis includes multifocal eosinophilic granuloma of the bone, polyostotic fibrous dysplasia, hyperparathyroidism and, less likely, metastatic carcinoma, lymphoma, sarcoidosis and neurofibromatosis. There are other types of angiomatoses to be considered. Gorhams disease, however, is unlikely because it is mainly lytic, whereas $C A B$ is expansile with more bone formation. Multiple osteochondromatosis is possible but not likely because of the apparent well defined sclerotic margins on the CT scan $(1,3,6)$.

\section{SUMMARY}

$\mathrm{CAB}$ is a rare disease that has to be considered in the differential diagnosis of patients who present with diffuse, multifocal cystic lesions with or without visceral involvement.
The diagnosis is usually established by bone biopsy, and the course depends on the presence or absence of visceral involvement. Osteoclastic bone resorption may contribute to the pathogenesis of the osteolytic lesions in $\mathrm{CAB}$; this has not been described previously.

\section{REFERENCES}

1. Schajowicz F, Aiello CL, Francone MV, Giannini RE. Cystic angiomatosis (hamartous haemolymphangiomatosis) of bone: A clinicopathological study of three cases. J Bone Joint Surg Br 1978;60:100-6.

2. Lateur L, Simoens CJ, Gryspeerdt S, Samson I, Mertens V, Van Damme B. Skeletal cystic angiomatosis. Skeletal Radiol 1996;25:92-5.

3. Levey DS, MacCormack LM, Sartoris DJ, Haghighi P, Resnick D, Thorne R. Cystic angiomatosis: case report and review of the literature. Skeletal Radiol 1996;25:287-93.

4. Ishida T, Dorfman HD, Steiner GC, Norman A. Cystic angiomatosis of bone with sclerotic changes mimicking osteoblastic metastases. Skeletal Radiol 1994;23:247-52.

5. Gramiak R, Ruiz G, Campetti FL. Cystic angiomatosis of the bone. Radiology 1957;69:347-53.

6. Boyle WJ. Cystic angiomatosis of bone: a report of three cases and review of the literature. J Bone Joint Surg Br 1972;54:626-36.

7. Morshed A, Mohit P. Cystic angiomatosis of the skull presenting with extradural pneumocephalus: Case report. J Neurosurg 1990;72:968-70.

8. Lomasney LM, Martinez S, Demos TC, Harrelson JM. Multifocal vascular lesions of bone: imaging characteristics. Skeletal Radiol 1996;25:255-61.

9. Reid AB, Reid IL, Johnson G, Hamonic M, Major P. Familial diffuse cystic angiomatosis of bone. Clin Orthop 1989;238:211-8.

10. Cohen MD, Rougraff B, Faught P. Cystic angiomatosis of bone: MR findings. Pediatr Radiol 1994;24:256-7. 


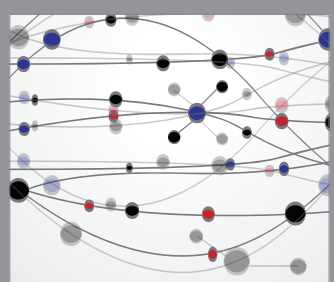

The Scientific World Journal
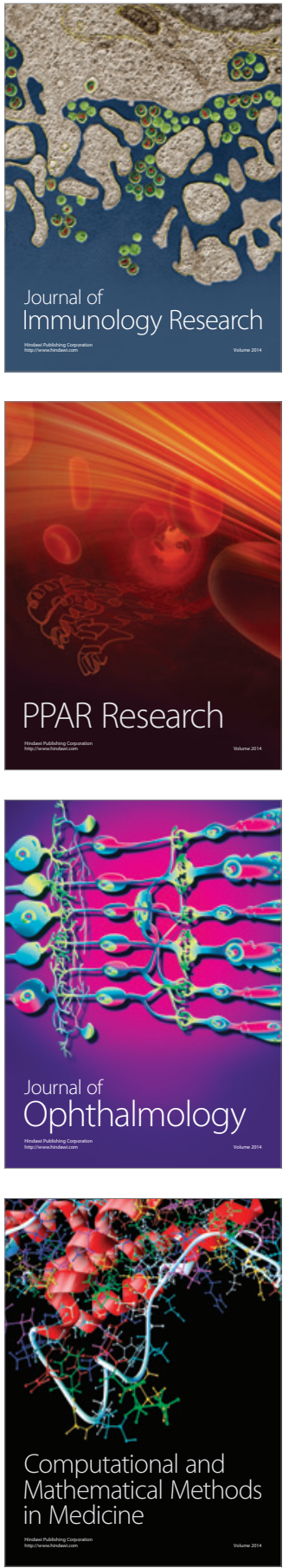

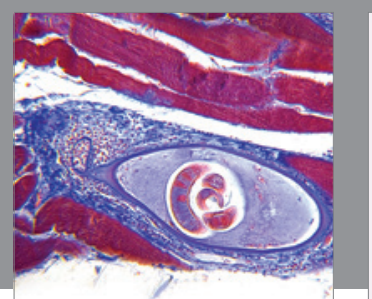

Gastroenterology Research and Practice

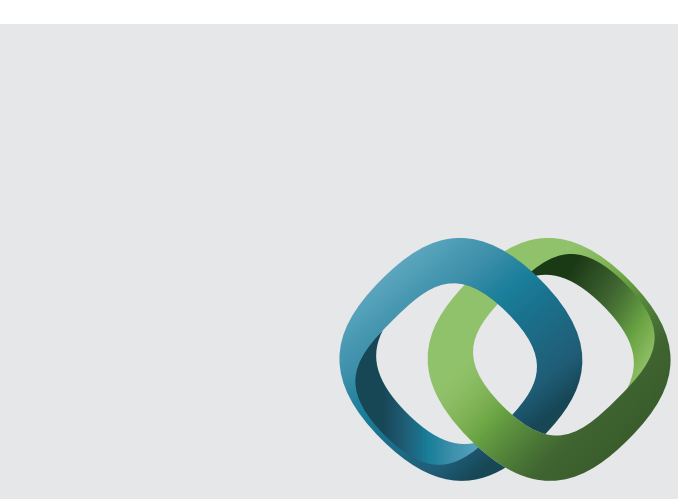

\section{Hindawi}

Submit your manuscripts at

http://www.hindawi.com
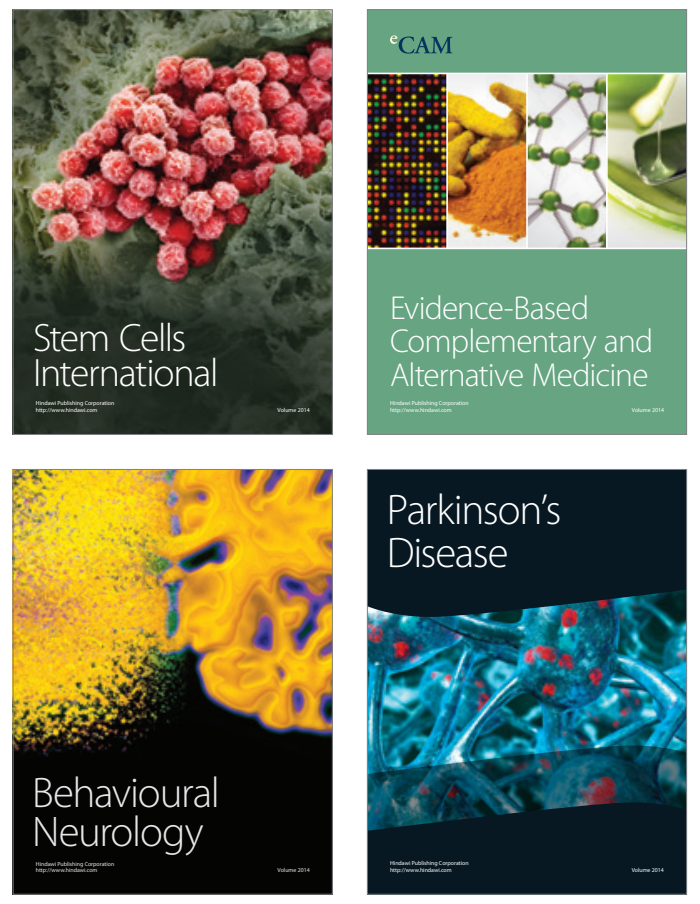
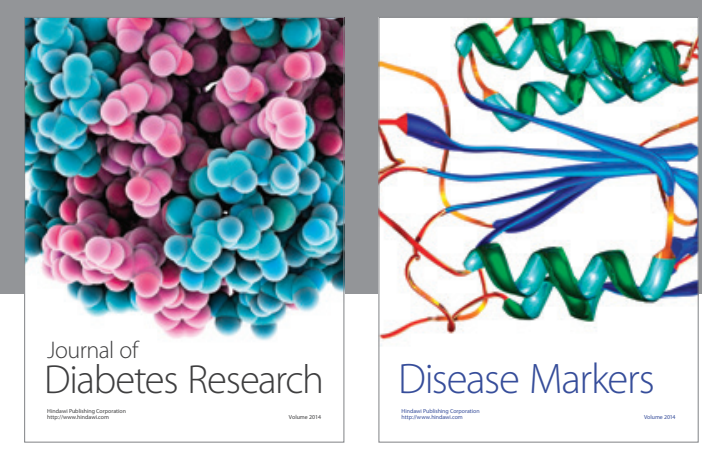

Disease Markers
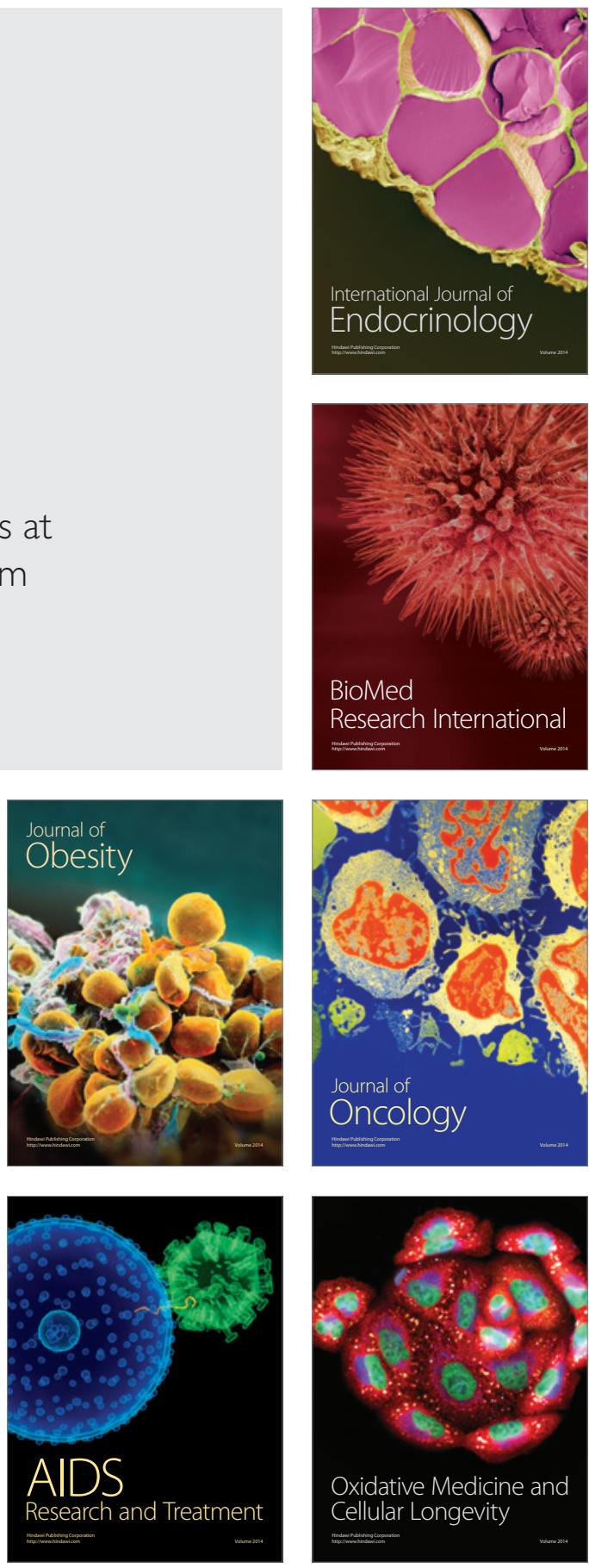